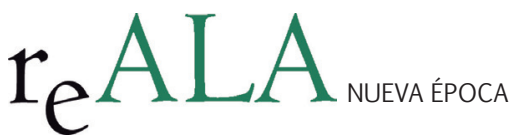

REALA, n 2, julio-diciembre 2014, ISSN: 1989-8975

DOI: http://dx.doi.org/10.24965/reala.voi2.10195

\title{
La concesión de servicios, nuevo objeto de regulación del Derecho Comunitario. Directiva 2014/23/UE de 26 de febrero de 2014 relativa a la adjudicación de contratos de concesión'
}

\author{
Francisca Villalba Pérez \\ Profesora Titular de Derecho Administrativo. Universidad de Granada \\ villalba@ugr.es
}

Recibido: I 7 de abril 20I4

Aceptado: 13 de junio 2014

\begin{abstract}
Resumen
Ante las dificultades económicas provocadas por el actual contexto de crisis, la Unión Europea, con el fin de reforzar los aspectos innovadores, ambientales y sociales de los servicios de interés general, manteniendo su continuidad con cierto grado de calidad, ha reaccionado aprobando un conjunto de medidas que pretenden incrementar la eficiencia del gasto público garantizando los mejores resultados en términos de relación calidad/precio. Una de ellas ha sido la Directiva relativa a la adjudicación de los contratos de concesión que será el objeto de estudio de este trabajo.

Palabras clave

Concesión de servicios, crisis económica, Directiva sobre concesiones, riesgo del concesionario, modificación de la concesión.

\section{The Service Concession New Object of Community law Regulation. Directive 2014/23/UE de $26^{\text {th }}$ february 2014 on the Award of Contract Concession}

\footnotetext{
Abstract

In view of the economic difficulties provoked by the current context of crisis, the European Union, in order to reinforce the innovative, environmental and social aspects of the services of general interest, supporting his continuity with certain degree of quality, has reacted approving a set of measures that try to increase the efficiency of the public expenditure guaranteeing the best results in terms of relation quality/ price. One of them has been the Directive on the adjudication of the contracts of concession that will be the object of study of this paper.

Keywords

Concession of services, economic crisis, Directive on concessions, risk of the concessionaire, modification of the concession.
}

El 15 de enero de 2014 el Parlamento Europeo aprobó por amplia mayoría tres resoluciones legislativas sobre las propuestas de Directivas del Parlamento Europeo y del Consejo publicadas el 20 de diciembre de 2011. La primera de ellas se refiere a la aprobación de la Directiva sobre contratación pública, que sustituirá a la Directiva 2004/18/CE sobre coordinación de los procedimientos de adjudicación de los contratos públicos de obras, de suministro, y de servicios. La segunda, a la Directiva relativa a la adjudicación de contratos de concesión, y la tercera, la Directiva sobre contratos celebrados por entidades que operan en los sectores del agua, energía, transportes y servicios postales, que sustituirá a la actual Directiva 2004/17/CE sobre coordinación de los procedimientos de adjudicación de contratos en los sectores del agua, de la energía, de los transportes y de los servicios postales. El BOUE de 28 de marzo de 2014 publicó las tres directivas relacionadas con la contratación del sector público. 


\title{
SUMARIO
}

\begin{abstract}
I. Punto de partida. Situación actual de los servicios públicos.- II. Creciente privatización de la gestión de los servicios públicos: 1. Consideraciones generales; 2. Disfunciones en la concesión de servicios provocadas por la crisis económica.- III. Nuevas perspectivas europeas.- IV Directiva 2014/23/UE de 26 de febrero de 2014 relativa a la adjudicación de contratos de concesión de servicios: 1. Objetivos perseguidos; 2. Concepto, ámbito de aplicación y exclusiones; 3. Principios generales y garantías procedimentales.- 4. El riesgo del concesionario como elemento central de la concesión: riesgo operacional de naturaleza económica; 5. Modificación de la concesión; 6. Subcontratación; 7. Resolución de las concesiones. Conclusiones.
\end{abstract}

\section{PUNTO DE PARTIDA. SITUACIÓN ACTUAL DE LOS SERVICIOS PÚBLICOS}

La actual crisis económica y financiera ha puesto de manifiesto el papel central que desempeñan los servicios públicos a la hora de garantizar la cohesión social y territorial en un momento en el que las posibilidades del sector público están sometidas a fuertes limitaciones presupuestarias, que obligan al regulador, gestor, y supervisor a garantizar una utilización óptima de los recursos disponibles con la finalidad de asegurar la continuidad, regularidad y estabilidad del servicio. Sin embargo, este elemental objetivo que implica una planificación y organización ordenada del servicio y una prestación eficiente ha quedado desdibujado para los ciudadanos que observan con cierta incertidumbre e inquietud las orientaciones del mercado y la respuesta de las instituciones públicas en general, españolas y europeas, a las gravísimas consecuencias de la crisis económica.

Esta pérdida de confianza y credibilidad en el mercado y en el sector público ha influido para que se reivindiquen la adopción de procesos de regeneración ética y de cambio, de nuevos patrones de comportamiento, del diseño de un nuevo sistema operativo ${ }^{2}$ con reestructuraciones internas encaminadas a eliminar burocracia y a flexibilizar y simplificar procedimientos, de una nueva metodología de actuación ${ }^{3}$ dotada de mayor autonomía en la gestión y de una nueva filosofía de la responsabilidad del gestor y del supervisor. Pero, todos estos cambios carecerán de validez si no existe un férreo control que permita contrastar la bondad y la transparencia del gasto público. Los tradicionales sistemas de control orientados a verificar el cumplimiento de la legalidad han de verse acompañados de rigurosas evaluaciones enhan del cumplimiento de los principios de economía, eficiencia, eficacia, y enjuiciar la responsabilidad del prestador y del supervisor. En España la intervención del Tribunal de Cuentas se produce tarde y sólo frente a determinadas cuantías económicas, y a la intervención previa le es imposible valorar el resultado de unos objetivos previstos pero no ejecutados ${ }^{4}$.

Esta necesidad de regeneración de los servicios públicos nos invita a preguntarnos hacia dónde giran las nuevas orientaciones, hacia fórmulas remozadas de provisión pública o hacia fórmulas que introduzcan mayor competencia en el mercado, más allá del Estado. El profesor ESTEVE PARDO ha manifestado que el mantenimiento del Estado social, constatados los elevados costes y desaparecidas las circunstancias históricas que lo hicieron posible, se presenta hoy como un objetivo difícilmente alcanzable, en riesgo de utopía. El nuevo modelo de Estado que ahora se vislumbra es el de Estado garante ${ }^{5}$, cuyo objetivo no es dispensar directamente determinadas prestaciones, sino garantizarlas de manera efectiva, corriendo a cargo en buena medida de sujetos privados. El modelo de Estado garante no contradice, en principio, los postulados fundamentales del Estado social, que

2 Desde hace algún tiempo se vienen reivindicando procesos de mejora y cambio que permitan mejorar la eficiencia y sostenibilidad de los servicios públicos. Véase GARCÍA SANCHEZ I. M., "Nueva gestión pública: evolución y tendencias”, Presupuesto y Gasto Público n 47, 2007 , pág. 38.

3 La participación, compromiso y satisfacción de los ciudadanos (no sólo de los consumidores o usuarios) es un elemento clave en la valoración de la eficacia y de la eficiencia de la prestación del servicio

4 Como señalan ARIMANY y MAGIDE en nuestro sistema constitucional el servicio público constituye un elemento esencial en la configuración del Estado social (artículo 1.1 de la Constitución). Pero este papel central no significa, en modo alguno, que no pueda y deba replantearse su concepción más tradicional, lo que no supone una renuncia a las exigencias del Estado social, sino una adaptación de estas a las nuevas circunstancias sociales y económicas. El servicio público es un medio para garantizar determinadas prestaciones esenciales para los ciudadanos y unos niveles mínimos de bienestar, y ni la inercia ni los prejuicios ideológicos deben impedir su replanteamiento y reforma cuando lo que se pretende es alcanzar del modo más eficiente posible los fines que le son propios: igualdad, accesibilidad, asequibilidad, regularidad, continuidad y progreso (ARIMANY E. y MAGIDE M., "El necesario replanteamiento de los servicios públicos. Dos ejemplos paradigmáticos: el abastecimiento de agua a poblaciones y la atención sanitaria especializada”, Actualidad jurídica Uría Menéndez, número extraordinario 2012, pág. 81).

5 El concepto de Estado garante comienza a diseñarse en Alemania hace unos años como alternativa al adelgazamiento del Estado y su costoso aparato administrativo. Uno de sus expositores más influyente es Andreas Vosskuhle, catedrático de Derecho Administrativo de la Universidad de Friburgo y en la actualidad presidente del Tribunal Constitucional (ESTEVE PARDO J., "Es sostenible el Estado de Bienestar", El País, 24 de octubre de 2013; La nueva relación entre Estado y sociedad: Aproximación al trasfondo de la crisis, Marcial Pons, Madrid, 2013). 
no requiere necesariamente de un monopolio o protagonismo del sector público; tampoco contradice nuestra Constitución, que reiteradamente afirma que los poderes públicos "garantizarán" una serie de prestaciones, sin imponerles la carga de su gestión directa.

Y este debate social sobre el papel del Estado ha influido para que las autoridades comunitarias, con el fin de reforzar los aspectos innovadores, ambientales y sociales de los servicios de interés general, manteniendo su continuidad con cierto grado de calidad, hayan reaccionado aprobando un conjunto de medidas de carácter normativo unas, y recomendaciones y propuestas otras, que serán el objeto de estudio de este trabajo. Las propuestas europeas pretenden incrementar la eficiencia del gasto público para garantizar los mejores resultados en términos de relación calidad/precio. Y este objetivo implica simplificar la regulación, establecer procedimientos más racionales y eficientes, facilitar la participación de las PYME y de operadores transfronterizos, y utilizar criterios y condiciones sociales que permitan la integración de colectivos desfavorecidos, la protección del medio ambiente, potenciando la eficiencia energética y la lucha contra el cambio climático ${ }^{6}$.

\section{CRECIENTE PRIVATIZACIÓN DE LA GESTIÓN DE LOS SERVICIOS PÚBLICOS}

\section{Consideraciones generales}

Los efectos de la actual crisis económica y financiera imponen un control más estricto del presupuesto, la deuda y el déficit público, y la búsqueda de mayor eficiencia en las formas de gestión que permitan reducir los costes y, por tanto, soslayar las dificultades económicas. La Ley de estabilidad presupuestaria7 que obliga al sector público a mantener un equilibrio contable e impone, en muchos casos, una rebaja de las aportaciones públicas al servicio ha propiciado la externalización de la gestión mediante fórmulas contractuales de gestión indirecta en las modalidades de concesión y de sociedad de economía mixta. Convirtiéndolas en instrumentos idóneos para atraer capital privado en sectores reservados a la gestión directa. No se trata de privatizar la actividad en el sentido de una despublificación sino de una privatización funcional limitada al ámbito de la gestión ${ }^{8}$. En palabras de GERARD MARCOU se trata de un conjunto de instituciones jurídicas que pretenden movilizar y atraer la inversión y el saber hacer industrial y técnico del sector privado, con el fin de dotar de los equipamientos públicos necesarios a la sociedad y la economía?.

La concesión de servicios públicos, modalidad paradigmática de la gestión indirecta, consiste en la transferencia al gestor indirecto (sujeto privado) de facultades originariamente administrativas. El concesionario, que gestionará el servicio a su propio riesgo y ventura, puede, incluso, dictar, por delegación de la Administración titular del servicio, actos susceptibles de impugnación mediante recurso administrativo. El servicio público concesionado ha de tener un contenido económico que lo haga susceptibles de explotación por empresarios particulares, quedando excluidos los servicios que impliquen ejercicio de la autoridad inherente a los poderes públicos ${ }^{10}$.

La sociedad de economía mixta permite a la Administración participar, por sí o por medio de una entidad pública, en concurrencia con personas naturales o jurídicas en la gestión del servicio público. La constitución de una sociedad de economía mixta con un empresario previamente elegido o la enajenación de parte de la totalidad de las acciones o participaciones sociales representativas del capital de una sociedad mercantil pública, supone una actuación compleja en la que, además de elegir al socio privado, se atribuye a la sociedad mixta un contrato de gestión de servicio público. La disposición adicional vigésima novena del TRLCSP siguiendo el sentido de la Comunicación de la Comisión Europea sobre colaboración público-privada institucionalizada"1 aclara que es perfectamente posible utilizar un solo procedimiento para elegir el socio y atribuir el contrato a la sociedad mercantil, de modo que no resulta necesario un procedimiento específico de adjudicación del contrato a la sociedad mixta para cumplir con las exigencias de transparencia del Derecho comunitario en materia de

6 En la contratación pública las autoridades de los Estados miembros podrán dar prioridad a consideraciones medioambientales, aspectos sociales o a la innovación, sin olvidar la calidad y el precio del objeto de la licitación. Los criterios de adjudicación que introducen las nuevas Directivas intentan hacer de la calidad de las prestaciones una cuestión fundamental.

7 Ley Orgánica 2/2012, de 27 de abril, de estabilidad presupuestaria y sostenibilidad financiera.

8 ARIMANY E. y MAGIDE M., "El necesario replanteamiento de los servicios públicos. Dos ejemplos paradigmáticos: el abastecimiento de agua a poblaciones y la atención sanitaria especializada”, Actualidad jurídica Uría Menéndez, número extraordinario 2012, págs. $84-85$

9 GERARD MERCOU y FRANCK MODERNE, Derecho de regulación, los servicios públicos y la integración regional, Universidad del Rosario, Bogotá, 2009, pág. 147.

10 En relación al ámbito de aplicación del contrato de gestión de servicio público, determina el artículo 275 TRLCSP que la Administración podrá gestionar indirectamente, mediante contrato, los servicios de su competencia, siempre que sean susceptibles de explotación por particulares. En ningún caso podrán prestarse por gestión indirecta los servicios que impliquen ejercicio de la autoridad inherente a los poderes públicos

11 Comunicación interpretativa de la Comisión relativa a la aplicación del Derecho comunitario en materia de contratación pública y concesiones a la colaboración público-privada institucionalizada (CPPI), 2008/C 91/02, DOUE de 12 de abril de 2008. 
contratación pública ${ }^{12}$.

En aquellos casos en los que el gestor privado reciba la remuneración económica del ente titular del servicio público y no pueda identificarse la explotación económica (artículos 281 TRLCSP) ${ }^{13}$, se abre paso la oportunidad de celebrar un contrato de colaboración entre el sector público y el sector privado, bien sea en su modalidad de colaboración simple o de colaboración institucionalizada. No obstante, hay que reconocer que, junto con las ventajas propias de su regulación, fundamentalmente, su carácter abierto, nuestro Derecho ha concebido al contrato de colaboración entre el sector público y el sector privado como un contrato excesivamente complejo en su preparación y adjudicación y de carácter subsidiario respecto de los demás tipos contractuales, lo que conduce en el ámbito de los servicios públicos locales a una escasa utilización.

Y en el marco de esta gestión indirecta de los servicios públicos, en concreto en el marco de la concesión, se están observando una serie de disfunciones provocadas fundamentalmente por la crisis económica en el que se desenvuelven. Nos referimos a la insuficiencia en la remuneración del concesionario, la financiación de la concesión, la suspensión del contrato, el secuestro y, en algunos supuestos, la resolución contractual. Cuestiones que sería conveniente analizar ante la inminente reforma contractual del sector público a que nos obliga la aprobación de las nuevas directivas europea sobre contratación pública, concesiones y la dirigida a los sectores especiales ${ }^{14}$.

\section{Disfunciones en la concesión de servicios provocadas por la crisis económica}

-En relación a la remuneración del concesionario. La regla general es hacerla efectiva a cargo de las tarifas satisfechas por los usuarios, que deberá ser suficiente para cubrir los costes de inversión, los costes de operación y una razonable tasa de retorno para los capitales propios y ajenos empleados en la concesión. La suficiencia tarifaria, constituye el principio general asumido normativamente, pero en servicios públicos con una demanda inelástica, dicha suficiencia se pone en peligro por bajadas de consumo imputables al menor gasto en tiempo de crisis, o, simplemente, por un consumo más responsable. Y estas bajadas de consumo tienen una relevante repercusión en el mantenimiento del equilibrio económico-financiero del servicio. Los costes asociados no bajan en la misma proporción que disminuye la demanda. El artículo 282 del TRLCSP incluye como causas de equilibrio económico financiero del contrato el ius variandi, el factum principis y los casos de fuerza mayor pero nada indica sobre el riesgo imprevisible. Aunque el $\mathrm{TS}^{15}$ se inclina claramente por la admisión del riesgo imprevisible como causa de reequilibrio, sigue sin resolverse de forma inequívoca si el impacto de la crisis económica, en forma de menos demanda en el servicio, constituye esa circunstancia sobrevenida no previsible que subvierte la economía de la concesión por causas ajenas a las partes, dando lugar a una compensación a cargo de la Administración concedente. Hecho que indudablemente genera inseguridad jurídica.

-En cuanto a la financiación de la concesión, debemos recordar la aversión actual de las entidades financieras a financiar todo aquello que implique un largo plazo de amortización, lo que está provocando serios problemas a los operadores que vuelven a pensar en figuras poco utilizadas hasta ahora, como la financiación mediante bonos u obligaciones o los fondos de inversión en infraestructuras y servicios públicos. El legislador no ha tratado convenientemente la financiación del concesionario de servicios públicos y sigue inédita, cualquier previsión normativa relativa a la financiación del contratista de gestión de servicios públicos. Tampoco ha cumplido el legislador su previsión de aprobar una ley que regule las distintas modalidades de captación de financiación en los mercados por los concesionarios de obras públicas o por los titulares de contratos de colaboración entre el sector público y el sector privado ${ }^{16}$.

12 Especifica la disposición adicional vigésimo novena del TRLCSP que los contratos públicos y concesiones podrán adjudicarse directamente a una sociedad de economía mixta en la que concurra capital público y privado, siempre que la elección del socio privado se haya efectuado de conformidad con las normas establecidas en esta Ley para la adjudicación del contrato cuya ejecución constituya su objeto, y en su caso, las relativas al contrato de colaboración entre el sector público y el sector privado, y siempre que no se introduzcan modificaciones en el objeto y las condiciones del contrato que se tuvieron en cuenta en la selección del socio privado.

13 Concreta el artículo 281 del TRLCSP que el contratista tiene derecho a las contraprestaciones económicas previstas en el contrato, entre las que se incluirá, para hacer efectivo su derecho a la explotación del servicio, una retribución fijada en función de su utilización que se percibirá directamente de los usuarios o de la propia Administración.

14 Recordemos que ante la reciente aprobación de las nuevas directivas en materia de contratación pública, concesiones y sectores especiales, los Estados miembros tienen un periodo de transposición de dos años desde su publicación en el DOUE. Periodo propicio para hacer las reformas y modificaciones necesarias.

15 La STS de 16 de mayo de 2011, Sala 3ª, Sección séptima, Recurso 566/2008, referida a una concesión de obra pública, da buena fe de ello. Sin embargo, posteriormente el mismo Tribunal Supremo ha matizado su doctrina sobre la admisión del principio de compensación integral (SSTS de 21 de noviembre y 12 de diciembre de 2011).

16 La Ley 30/2007, de Contrato del Sector Público dejó subsistentes las previsiones del anterior Texto Refundido de la Ley de Contratos de las Administraciones Públicas (RD Legislativo 2/2000), referidas, únicamente, a la financiación del concesionario de obra pública, previsiones que, por otra parte, han tenido que reincorporarse de nuevo formalmente al TRLCSP, al no cumplir la propia Ley de Contratos del Sector Público su previsión de aprobar una Ley que regulase las distintas modalidades de captación de financiación en los mercados por los concesionarios de obras públicas o por los titulares de contratos de colaboración entre el sector público y el sector privado. 
Junto a estos problemas han aflorado también algunas debilidades que en épocas de normalidad económica no presentaban problema alguno en relación a la suspensión, recate, secuestro y resolución del contrato de concesión de servicios, debido a una utilización incorrecta e indiscriminada de algunas de estas figuras, cuando el concepto, contenido, los efectos y el régimen jurídico de cada una de ellas es completamente distinto.

Sería bueno por ello que recordáramos las repercusiones legales de cada una de estas figuras jurídicas. La suspensión del servicio implica la paralización o interrupción temporal de la ejecución del contrato. El rescate del servicio implica una decisión unilateral adoptada discrecionalmente por la Administración concedente que da por terminada la concesión antes de la fecha pactada a pesar de la buena gestión del concesionario asumiendo la Administración concedente la prestación del servicio directamente. Se trata de una decisión unilateral debidamente motivada por la que el órgano de contratación pone fin a la concesión del servicio por razones de interés público sin que el concesionario haya incurrido en irregularidad alguna. Por el contrario el secuestro del servicio implica una medida coyuntural o temporal adoptada por la Administración concedente para supuestos en que el concesionario haya incurrido en una infracción grave que pone en peligro la buena prestación del servicio. El secuestro implica la intervención temporal del servicio a costa del concesionario. Por último la caducidad del servicio, supone la extinción anticipada del servicio producida por una infracción gravísima de las obligaciones esenciales del concesionario o cuando se haya producido un secuestro previo y el concesionario vuelva a incidir en las mismas infracciones que lo determinaron o en otras similares. Suele configurarse como un supuesto de resolución contractual.

La práctica más habitual en los últimos años ha sido el sistemático incumplimiento de las obligaciones de pago por parte de las Administraciones públicas a los concesionarios y contratistas, que han respondido, en muchos casos, con la suspensión del contrato. Esta facultad de suspender la ejecución del contrato por parte del contratista está contemplada en nuestro ordenamiento jurídico con la finalidad de aminorar los efectos de un retraso cualificado de la Administración en el cumplimiento de su obligación de pago ${ }^{17}$. En concreto, nuestra normativa aplicable a todos los contratos administrativos (artículo 216.5 del TRLCSP), especifica que si la demora en el pago fuese superior a cuatro meses, el contratista podrá proceder a la suspensión del cumplimiento del contrato comunicándoselo a la Administración con un mes de antelación ${ }^{18}$. Y la Administración deberá levantar un acta en la que se consignarán las circunstancias que han motivado la suspensión y la situación de la ejecución del contrato, y abonará al contratista los daños y perjuicios efectivamente sufridos (artículo 220 TRLCSP). Este sistema, es el sistema general aplicable a todos los contratos administrativos.

No obstante, con la finalidad de proteger la regularidad y continuidad en la prestación del servicio, nuestra normativa contractual pública no prevé la suspensión del cumplimiento del contrato de gestión de servicio público ${ }^{19}$. El artículo 284 del TRLCSP, precepto específico del contrato de gestión de servicios públicos, concreta que si la Administración no hiciere efectiva al contratista la contraprestación económica o no entregare los medios auxiliares a que se obligó en el contrato dentro de los plazos previstos el contratista tendrá derecho al interés de demora a partir del vencimiento del plazo previsto para su entrega, así como de los daños y perjuicios sufridos de conformidad con lo establecido en el artículo 216 TRLCSP, estableciendo el artículo 286 TRLCSP el plazo para que el contratista pueda instar la resolución del contrato en 6 meses $^{20}$.

Pues bien, ante las suspensiones adoptadas por el concesionario de servicios ante el incumplimiento de pago por parte de la Administración se han produciendo casos de intervención del servicio (secuestro) para evitar conflictos ciudadanos y costes políticos, haciendo recaer durante largo tiempo la financiación del servicio secuestrado a cargo del contratista ${ }^{21}$. Lo que ha agravado aún más la situación económica del concesionario,

17 Recordemos que el artículo 281 del TRLCSP determina que el contratista tiene derecho a las contraprestaciones económicas previstas en el contrato, entre las que se incluirá, para hacer efectivo su derecho a la explotación del servicio, una retribución fijada en función de su utilización que se percibirá directamente de los usuarios o de la propia Administración

18 Si la demora en el pago fuese superior a cuatro meses, el contratista podrá proceder, en su caso, a la suspensión del cumplimiento del contrato, debiendo comunicar a la Administración, con un mes de antelación, tal circunstancia, a efectos del reconocimiento de los derechos que puedan derivarse de dicha suspensión, en los términos establecidos en esta Ley

19 A pesar de ello en ocasiones son los propios pliegos de cláusulas administrativas particulares los que, obviando los preceptos antes citados, suelen reconocer expresamente la facultad de suspensión de la prestación por parte del gestor indirecto en los mencionados casos de demora de la Administración en el pago.

20 Plazo que ha equiparado al contrato de gestión de servicios públicos con el resto de contratos administrativos. Hasta hace poco tiempo el plazo previsto en el artículo 216 para poder instar la resolución del contrato por incumplimiento de la Administración de su obligación de pago era de 8 meses. La Ley 14/2013, de 27 de septiembre, de apoyo a los emprendedores y su internacionalización ha modificado el artículo 216.6 del TRLCSP acortando el plazo para instar la resolución del contrato a 6 meses.

21 Si el concesionario suspendiera el servicio, la Administración podrá instar la intervención de la concesión. El artículo 285 del TRLCSP determina que si del incumplimiento por parte del contratista se derivase perturbación grave y no reparable por otros medios en el servicio público y la Administración no decidiese la resolución del contrato, podrá acordar la intervención del mismo hasta que aquélla desaparezca. En todo caso, el contratista deberá abonar a la Administración los daños y perjuicios que efectivamente le haya irrogado 
cuando en realidad se trata de una causa especifica de resolución del contrato de gestión de servicios públicos²2.

En otras ocasiones la Administración ha utilizado la figura del rescate, no por razones de interés público que avalen gestionar directamente la prestación del servicio tal como ordena nuestra normativa (artículo 287.2 TRLCSP), sino para retomar el control del servicio y volver a licitar la concesión por un tiempo lo suficientemente prolongado como para exigir un nuevo y sustancioso canon al nuevo adjudicatario. Cuando en realidad se trata de una extinción anticipada del contrato mediante su resolución. Recordemos que además de las causas generales de resolución de los contratos administrativos ${ }^{23}$ la normativa contempla unas causas específicas de resolución del contrato de gestión de servicios públicos y como efecto común a tres de ellas, la Administración, sin perjuicio de compensar al concesionario por la parte no amortizada de su inversión, le indemnizará por los daños y perjuicios que se le irroguen, incluido el lucro cesante o beneficios futuros, en los términos que el artículo 288.4 TRLCSP indica.

Ante este incumplimiento de las obligaciones contractuales provocado por el contratista y por la Administración concedente se produce una concurrencia de causas de resolución no contemplada en el TRLCSP. No obstante, la Administración concedente, encargada de velar por el interés general o público, tiene prioridad en la aplicación de dichas causas de resolución Se trata como vemos de debilidades de la regulación en unos casos y de mala praxis en otros que deberían ser replantadas en la medida que disuaden a potenciales inversores y encarecen sustancialmente la financiación del servicio, generan inseguridad jurídica e innumerables conflictos entre la Administración y el contratista con el coste a ello inherente, y el inevitable impacto negativo en la colaboración entre las partes que debe presidir la ejecución del contrato.

\section{NUEVAS PERSPECTIVAS EUROPEAS}

Y en este contexto de crisis económica con fuerte impacto en la capacidad de las empresas y de los Gobiernos para financiar proyectos de inversión que ha obligado a los gestores de servicios públicos a establecer limitaciones presupuestarias y a sanear sus precarias economías, la Comisión Europea, con la idea de consolidar la dimensión social del mercado único, y aclarar y recordar las normas aplicables ha elaborado unas directrices para que los Estados miembros puedan seguir prestando servicios esenciales a pesar de las malas condiciones económicas. El conjunto de medidas europeas de carácter normativo unas, y recomendaciones y propuestas otras, pretenden reforzar los aspectos innovadores, ambientales y sociales de los servicios ${ }^{24}$, incrementando la eficiencia del gasto público para garantizar los mejores resultados en términos de relación calidad/precio 25 .

En armonía con la denominada Estrategia Europa 2020 para un crecimiento inteligente, sostenible e integrador, la Comisión Europea en su Comunicación de 13 de abril de 2011, Acta del Mercado Único: 12 prioridades para estimular el crecimiento y reforzar la confianza, señalaba la necesidad de una revisión y modernización del marco normativo de la contratación pública para flexibilizar la adjudicación de los contratos públicos y para que éstos pudieran servir mejor como apoyo de otras políticas.

Para ello se efectuaron consultas a los sectores interesados que incidieron sobre la necesidad de simplificar

22 El artículo 286 del TRLCSP contempla como causas de resolución del contrato de gestión de servicios público, además de las causas generales señaladas en el artículo 223 TRLCSP, salvo las causas previstas en sus letras d) y e), las siguientes:

a) La demora superior a seis meses por parte de la Administración en la entrega al contratista de la contraprestación o de los medios auxiliares a que se obligó según el contrato.

b) El rescate del servicio por la Administración.

c) La supresión del servicio por razones de interés público.

d) La imposibilidad de la explotación del servicio como consecuencia de acuerdos adoptados por la Administración con posterioridad al contrato.

Prescribiendo el artículo 288.4 del TRLCSP que, sin perjuicio de compensar al concesionario por la parte no amortizada de su inversión, la Administración le indemnizará por los daños y perjuicios que se le irroguen, incluido el lucro cesante o beneficios futuros, en los términos que el propio precepto indica

23 El artículo 223 g) TRLCSP recoge, como causa de resolución aplicable al conjunto de contratos administrativos, la imposibilidad de ejecutar la prestación en los términos inicialmente pactados o la posibilidad cierta de producción de una lesión grave al interés público de continuarse ejecutando la prestación en esos términos, cuando no sea posible modificar el contrato conforme a lo dispuesto en el título $V$ del Libro I. El apartado 5 del artículo 225 del mismo TRLCSP indica que, en tal supuesto, el contratista tendrá derecho a una indemnización del 3 por ciento del importe de la prestación dejada de realizar, salvo que la causa sea imputable al contratista

24 Condiciones sociales como la protección del medio ambiente, mayor eficiencia energética, lucha contra el cambio climático, integración de colectivos desfavorecidos

25 La crisis económica ha cambiado la estructura del mercado y ha puesto de relieve algunas carencias de las economías europeas y ciertos signos de fatiga y cansancio en la integración europea, que han aumentado los sentimientos y aspiraciones de nacionalismos económicos y el desencanto respecto al mercado único, acabando con muchas de las ventajas obtenidas en los últimos años. 
las normas de contratación, incrementar su eficiencia y eficacia, y, hacer que se adapten mejor a la evolución del contexto económico y social. Y se adoptaron tres propuestas de Directivas del Parlamento Europeo y del Consejo aparecidas a finales de diciembre de 2011 (días 20 y 21) relativas a la contratación pública la primera, a la contratación por las entidades que operan en los sectores del agua, la energía, los transportes y los servicios postales, la segunda, y, la tercera, y más novedosa referente a la adjudicación de los contratos de concesión. Las dos primeras sustituirán a las actuales directivas 2004/18/CE y 2004/17/CE.

Este conjunto de directrices comunitarias han quedados plasmadas en un primer paquete de reformas generales relacionadas con el mercado interior, y en un segundo, de carácter más específico, dirigido a clarificar la concesión de ayudas públicas a los servicios de interés general.

\section{A) Reformas generales relacionadas con el mercado interior}

-Estrategia UE 2020 para un crecimiento inteligente, sostenible e integrador. Comunicación de la Comisión Europea de 3 de marzo de 2010.

-Agenda Territorial Europea 2020, de 19 de mayo de 2011.

- Doce prioridades para estimular el crecimiento y reforzar la confianza en el mercado único europeo. Comunicación de la Comisión adoptada en abril de 2011.

-Marco de calidad de los servicios de interés general. Comunicación de la Comisión de 20 de diciembre de 2011.

-Hacia un mercado europeo de la contratación pública más eficiente. Libro Verde de 27 de enero de 2012.

-Directiva 2014/24/UE de 26 de febrero de 2014 sobre contratación pública.

-Directiva 2014/23/UE de 26 de febrero de 2014 relativa a la adjudicación de contratos de concesión.

-Directiva 2014/25/UE de 26 de febrero de 2014 sobre contratos celebrados por entidades que operan en los sectores del agua, energía, transportes y servicios postales aprobada por el Parlamento Europeo el 15 de enero de 2014 .

La Estrategia Europa 2020 propone tres prioridades que se refuerzan mutuamente: a) un crecimiento inteligente basado en el conocimiento y la innovación; b) un conocimiento sostenible que haga un uso más eficaz de los recursos; c) un crecimiento integrador que favorezca la cohesión social y territorial. Pretende potenciar un mercado abierto de servicios reforzando la prestación eficiente y sostenible con la finalidad de afianzar e impulsar una mayor cohesión social y territorial y considera que la contratación pública desempeña un papel clave en la utilización eficiente de los fondos públicos, y el contrato de concesión en particular impulsa el desarrollo estructural a largo plazo de infraestructuras y servicios estratégicos, fomenta la competencia en el mercado interior, y permite aprovechar por el sector público el avance industrial, técnico e innovador del sector privado.

La Comunicación sobre un marco de calidad de los servicios de interés general ${ }^{26}$ intenta proporcionar un marco de acción mediante tres objetivo ${ }^{27}: 1^{\circ}$ ) Aumentar la claridad y la seguridad jurídicas de las normas aplicables a estos servicios; $2^{\circ}$ ) Proporcionar las herramientas que permitan a los Estados miembros garantizar que los ciudadanos tiene acceso a servicios esenciales y revisar la situación periódicamente; y $3^{\circ}$ ) Fomentar iniciativas de calidad, en particular, para los servicios sociales que cubren necesidades especialmente importantes, reconociendo el importante papel que estos servicios desempeñan en la difícil situación actual²8.

La Comunicación explica que el marco comunitario sobre los servicios de interés general pretende acabar con las incertidumbres protegiendo el derecho de acceso a los ciudadanos europeos a los servicios esenciales, para reforzar la dimensión social del mercado y la específica misión de servicio público que cumplen. Para ello expone cómo actuar para que la normativa comunitaria con impacto en la organización, financiación y prestación de los servicios de interés general no sólo no obstaculice su misión de servicio público sino que la facilite y permita. Añadiendo que en la prestación y financiación de los servicios sociales de interés general las fundaciones de utilidad pública desempeñan un papel cada vez mayor. No obstante, reconoce las dificultades para establecer fundaciones en otros Estados miembros con el objetivo de aunar esfuerzos y activos. Por ello propone la creación de fundaciones de interés general a escala transfronteriza, sujetas a una adecuada supervisión, mediante la

26 El Comité Económico y Social lamenta profundamente el título de la Comunicación, que resulta confuso y sugiere más de lo que ofrece su contenido. Confuso porque la expresión "marco de calidad" tiene un significado distinto al contenido que se le suele dar al término de "calidad", que no es abordado en absoluto en la Comunicación y pueden confundir a los destinatarios (Dictamen $n^{\circ} 481$ de 24 de mayo de 2012, DOUE, de 31 de julio de 2012, C-229/100, apartado $4^{\circ}$ )

27 Véase el Dictamen del Comité Económico y Social Europeo № 481, de 24 de mayo, de 2012.

28 Para cumplir con estos objetivos, la Comunicación se ha visto acompañada de la aprobación de un paquete de nuevas normas sobre ayudas públicas y de una revisión de las normas de contratación pública y concesiones. 
elaboración de un estatuto de fundación europea que, con carácter adicional y optativo, se regiría por normativa comunitaria, complementada por la legislación nacional de los Estados miembros, con el fin de facilitar las actividades transfronterizas de las fundaciones que presten o contribuyan a prestar servicios sociales de interés general en la UE. Mediante estas fundaciones los Estados miembro reducirían las cargas administrativas derivadas de la complejidad de realizar operaciones en varios Estados.

Este paquete de reformas prevé un tratamiento específico para los servicios sociales y sanitarios, a los que sujeta a un régimen más sencillo y flexible. Aplicándoles unos umbrales más elevados, y obligándolos exclusivamente a cumplir los requisitos de transparencia y de igualdad de trato ${ }^{29}$.

En definitiva, la Comisión Europea mediante la citada Comunicación pretende aclarar los conceptos básicos pertinentes en relación a los servicios de interés económico general; busca simplificar las normas relativas a las ayudas estatales para los pequeños servicios organizados a nivel local y que tienen un efecto limitado en el comercio entre Estados miembros; e introduce un tratamiento más específico para determinados servicios, a fin de diferenciar mejor los servicios de tamaño medio y los servicios sociales, por una parte, y, por otra, las actividades a gran escala cuya dimensión abarque toda la UE, que estarán sujetas a un control más efectivo desde el punto de vista de la competencia ${ }^{30}$.

La nueva Directiva sobre contratación pública, Directiva 2014/24/UE de 26 de febrero de 2014, aprobada por el Parlamento Europeo el 15 de enero de 2014 busca flexibilizar y simplificar los procedimientos contractuales poniendo a disposición de los poderes adjudicadores algunas técnicas o herramientas de contratación no previstas en la Directiva de 2004. Para ello:

-Acorta los plazos en la presentación de las proposiciones del contratista que permitirán una contratación más rápida y racional.

-Introduce un nuevo procedimiento denominado "asociación para la innovación" previsto para adquirir productos y servicios innovadores que permitirá a las autoridades públicas abrir licitaciones para problemas específicos sin anticipar la solución de los mismos, lo que deja margen a la autoridad contratante y al licitador para que propongan ellos mismos las soluciones.

-Fomenta la participación de PYMES admitiendo la división de los contratos en distintos lotes.

-Contempla la implantación de un documento europeo de contratación pública basado en declaraciones del propio empresario que permitirá que sólo el adjudicatario deba proporcionar la documentación original para acreditar el cumplimiento de determinados requisitos ${ }^{31}$.

-Incluye normas más estrictas en la subcontratación para garantizar que los subcontratistas cumplen las obligaciones medioambientales, sociales y laborales, establecidas por la legislación de la Unión, la legislación nacional, velando a la vez por que haya cierta transparencia en la cadena de subcontratación para facilitar a los poderes adjudicadores y entidades adjudicadoras información sobre quien está presente en la obras o en el servicio ${ }^{32}$.

-Por último, la Directiva sobre contratación pública prevé la designación de una única autoridad nacional de supervisión encargada de examinar el texto de los contratos a fin de detectar pautas sospechosas, asistir al órgano de contratación en la preparación y desarrollo de los procedimientos de contratación pública, y velar por el cumplimiento y aplicación de la normativa europea.

\section{B) Concesión de ayudas públicas a los servicios de interés general}

El segundo paquete de reformas y propuestas va dirigido a clarificar el sistema de ayudas públicas destinadas a compensar los costes netos generados por la misión de servicio público que tienen encomendada los servicios de interés general. El coste neto de estas ayudas debe calcularse basándose en la diferencia entre los gastos ocasionados por la ejecución del servicio público y los ingresos obtenidos. No obstante, estas compensaciones económicas pueden declararse contrarias al Derecho comunitario de competencia si la Comisión Europea considera

29 Véanse los apartados 23, 24 y 41 de la Resolución del Parlamento Europeo, de 5 de julio de 2011, sobre el futuro de los servicios sociales de interés general.

30 Para garantizar que todos los ciudadanos sigan teniendo acceso a servicios esenciales de alta calidad y a precios asequibles, considera la Comisión necesario abrir a la competencia sectores que no han sido todavía liberalizados o no lo han sido completamente (servicios bancarios básicos, servicios postales, transporte de viajeros, energía, telecomunicaciones).

31 El proceso de licitación para las compañías será más simple, con un documento único europeo de contratación pública basado en declaraciones del propio empresario, lo que permitirá que sólo el adjudicatario deba proporcionar la documentación original. Esto debe reducir la carga administrativa de las empresas en más de un 80 por ciento, según las estimaciones de la Comisión.

32 Los contratistas que no cumplan con la legislación laboral comunitaria podrán ser excluidos de las licitaciones. 
que superan los costes y que la financiación pública otorgada constituye una ventaja económica que no se justifica para sus beneficiarios. El control de las ayudas estatales tiene por objeto garantizar que una compensación por servicio público no supera el nivel necesario para cubrir los gastos de la empresa encargada de la prestación del servicio, incluido un beneficio razonable.

En la situación de escasez de recursos económicos y crisis financiera que nos encontramos, la selección adecuada de proyectos que merezcan recibir apoyo económico público es un reto prioritario para la Comisión Europea y para los Estados miembros. Sin embargo, el actual régimen de control de ayudas públicas muestra claras deficiencias para afrontar este reto: el procedimiento es poco ágil, la normativa es difícil de aplicar y se ha venido generando en este sector gran inseguridad jurídica. Por lo que la Unión Europea ha llevado a cabo un proyecto de modernización del régimen de ayudas de Estado mediante la aprobación de un paquete de reformas que prevén una modificación integral del régimen aplicable ${ }^{33}$. Las principales iniciativas europeas relacionadas con la concesión de ayudas públicas a los servicios de interés general han quedado plasmadas en los siguientes textos:

-Guía de la Comisión Europea de 24 de abril de 2013 para la aplicación por los Estados miembros de las reglas y normas sobre ayudas estatales, contratación pública, y el mercado interior de los servicios de interés general y en particular de los servicios sociales de interés general.

-Reglamento UE 360/2012 de la Comisión, de 25 de abril de 2012, relativo a la aplicación de los artículos 107 y 108 del TFUE a las ayudas de minimis concedidas a empresas que prestan servicios de interés económico general

-Decisión 2012/21/UE de la Comisión de 20 de diciembre de 2011, relativa a la aplicación de las disposiciones del artículo 106.2 del TFUE a las ayudas estatales en forma de compensación por servicio público, concedidas a algunas empresas encargadas de la gestión de servicios de interés económico general.

-Comunicación de la Comisión de 11 de enero de 2012, Marco de la Unión Europea sobre ayudas estatales en forma de compensación por servicio público

-Comunicación de la Comisión Europea de 20 de diciembre de 2011, relativa a la aplicación de las normas de la UE en materia de ayudas estatales a las compensaciones concedidas por la prestación de servicios de interés económico general.

Los objetivos que pretenden alcanzarse con este paquete de reformas pueden resumirse en cuatro puntos:

a) simplificar y consolidar el régimen normativo aplicable, estableciendo criterios de coherencia mínimos en el análisis de la compatibilidad con el mercado interior de los distintos regímenes y tipos de ayudas estatales;

b) reforzar la seguridad jurídica de los operadores, estableciendo conceptos claros sobre el concepto de ayudas de Estado y sobre las categorías de ayudas de Estado que no precisan autorización ex ante de la Comisión;

c) agilizar el procedimiento de revisión de las ayudas de Estado, al permitir a la Comisión que centre su investigación solo en los casos de mayor impacto y amplíe los supuestos de autorización automática de ayudas públicas; $y$

d) reforzar las facultades de investigación y análisis de la Comisión.

\section{DIRECTIVA RELATIVA A LA ADJUDICACIÓN EL CONTRATO DE CONCESIÓN. DIRECTIVA 2014/23/UE DE 26 DE FEBRERO DE 2014}

Con la finalidad de aumentar la claridad y la seguridad jurídicas de las normas aplicables a las concesiones, proporcionar a los Estados miembros las herramientas que les permitan garantizar el acceso a servicios esenciales, y fomentar iniciativas de calidad para los servicios que cubren necesidades especialmente importantes, la Unión Europea ha aprobado la Directiva relativa a las adjudicaciones de concesiones, que viene a reconocer el importante papel que los servicios públicos desempeñan en la difícil situación actual.

\section{Objetivos perseguidos por la Directiva}

A grandes rasgos los objetivos fundamentales que persigue la Directiva son:

- Introducir una nueva regulación en el ámbito de la Unión Europea del contrato de concesión de servicios con la finalidad de dotar de mayor seguridad jurídica al sector. Hasta ahora las concesiones de obra se

33 Véase VIDAL MARTÍNEZ P., “La reforma del régimen de ayudas de Estado en la Unión Europea”, Actualidad Jurídica Uría-Menéndez 34, 2013. 
encontraban sujetas de forma parcial a la Directiva clásica de contratación pública, la Directiva 2004/18/ $\mathrm{CE}^{34}$, mientras que las concesiones de servicios estaban sujetas exclusivamente a los principios del TFUE en particular los de libre circulación de mercancías, libertad de establecimiento y libre prestación de servicios, así como los principios que se derivan de ellos, igualdad de trato, no discriminación, reconocimiento mutuo, proporcionalidad y transparencia (artículos 43 a 4935).

Señala la Directiva que la concesión de servicios no contaba con una regulación a nivel europeo a pesar de representar un alto porcentaje de la colaboración público-privada y de que su uso se ha visto incrementado en los últimos años como consecuencia de las limitaciones presupuestarias de gasto público. La falta de armonización en este sector constituía una traba para el acceso al mercado de las concesiones debido a la inexistencia de una definición clara homogénea y precisa de lo que debe entenderse por concesión y por la ausencia de disposiciones comunitarias sobre los procedimientos y reglas a seguir. La nueva regulación pretende estimular la inversión privada mediante la colaboración público-privada; superar las ineficiencias detectadas que han supuesto cierto falseamiento del mercado interior, la limitación de acceso de las empresas europeas a los contratos de concesión y la falta de seguridad jurídica. Objetivos todos ellos que figuran en la Estrategia Europa 2020, hacia un crecimiento inteligente, sostenible e integrador.

- El segundo objetivo es unificar el concepto de concesión de obra y de servicio que cada Estado miembro utilizaba de forma descoordinada restándole fluidez al mercado único. Para ello parte la Directiva de la unificación conceptual de las concesiones de obras y servicios estableciendo una regulación conjunta que incide en la transferencia de riesgos hacia el concesionario e incorpora algunas previsiones sobre los procedimientos de adjudicación para favorecer la transparencia, la igualdad y la concurrencia de los operadores. Incluyendo una nueva regulación de las modificaciones contractuales durante la vigencia de la concesión.

- El tercer objetivo es diferenciar el contrato de concesión del contrato público por el mayor riesgo que la operación implica; por la mayor complejidad jurídica de la relación entablada entre el concesionario y los poderes o entidades adjudicadores como consecuencia de la larga duración de la concesión; y por la mayor flexibilidad que requiere la ejecución de la concesión. Para ello distingue la Directiva entre el “contrato de concesión" y el "contrato público36", caracterizando al primero por la asunción por parte del concesionario de los riesgos y responsabilidades que tradicionalmente recaen o son competencia de los poderes y entidades adjudicadoras, señalando que la característica fundamental de la concesión es la transferencia al contratista de la totalidad o, al menos, una parte significativa del riesgo operacional de carácter económico de la concesión, circunstancia no contemplada o, al menos, no con esa intensidad, en los denominados contratos públicos. El rasgo esencial que caracteriza a la concesión no es el objeto del contrato, la explotación del servicio, nota que también posee el contrato de servicios, sino la transferencia económica en la prestación del servicio al concesionario que en el contrato de servicios no existe. Esta transferencia del riesgo viene a ser lo que en nuestro sistema interno conocemos como principio de "riesgo y ventura" del contratista en la ejecución del contrato administrativo, y que la Directiva conceptúa como "riesgo operacional de carácter económico".

La relación concesionario-concedente es mucho más compleja que cualquier otra relación contractual pública al tratarse generalmente de contratos de larga duración que, por su objeto, requieren mayor flexibilidad en su ejecución. Esta diferencia entre contratos públicos y concesiones parece ser la justificación de que se haya producido un tratamiento normativo diferenciado entre ambas instituciones contractuales. No obstante, el régimen previsto para las concesiones no alcanza la extensión ni el nivel de detalle que la regulación comunitaria de los contratos públicos de obras, servicio y suministros ${ }^{37}$. Por

34 Actualmente a las concesiones de obras, se les aplican los artículos 56 a 59 de la Directiva 2004/18/CE, de 31 de marzo de 2004, sobre coordinación de los procedimientos de adjudicación de los contratos públicos de obras, de suministro y de servicios, y el artículo 3 de la Directivas 93/37/CEE que impone determinadas obligaciones en materia de publicidad, como la convocatoria previa obligatoria de operadores interesados o la obligación relativa al plazo mínimo de recepción de las candidaturas, siempre que la concesión supere los 5.186.000 de euros.

35 En la medida que dichos servicios presenten cierto interés transfronterizo. Si no existiese ese interés el contrato puede quedar fuera del ámbito de aplicación de las disposiciones del TFUE. Véase la Comunicación interpretativa de la Comisión sobre el Derecho comunitario aplicable en la adjudicación de contratos no cubiertos o sólo parcialmente cubiertos por las Directivas sobre contratación pública de 1 de agosto de 2006, página 2. También puede consultarse la Guía de la Comisión Europea de 24 de abril de 2013 para la aplicación por los Estados miembros de las reglas y normas sobre ayudas estatales, contratación pública, y el mercado interior de los servicios de interés general y en particular de los servicios sociales de interés general

36 Manifestando que esta falta de distinción ha sido fuente continua de inseguridad jurídica y origen de numerosas sentencias del TJUE.

37 La Directiva regula cuidadosamente la publicidad de los contratos de concesión, distinguiendo los anuncios de información previa, 
ello, la Directiva no prejuzga ni impone una determinada forma de organizar o prestar los servicios o, en su caso, de ejecutar las obras por parte de los Estados miembros ${ }^{38}$, pero sí establece normas particulares para el caso de que se opte por la vía de la gestión indirecta.

- Por último, el artículo 2 de la Directiva deja libertad a las autoridades públicas de los Estados miembros para organizar los servicios públicos. Los Estados son libres, dentro del respeto de los principios derivados del TFUE (igualdad de trato, no discriminación, transparencia y libre circulación de personas) para organizar la prestación de servicios, ya sea como servicios de interés económico general, como servicios no económicos de interés general, o como una combinación de ambos ${ }^{39}$.

En líneas generales la Directiva establece normas en materia de selección de operadores económicos, criterios de adjudicación, y ciertos elementos relativos a la ejecución aumentando la transparencia mediante la publicación en el DOUE de todos los contratos de concesión de valor igual o superior a 5.186.000 euros, en la que figure un mínimo de información que debe facilitarse a todos los potenciales licitadores. Y persigue los siguientes objetivos:

a) Limitar la discrecionalidad de los órganos de contratación estableciendo obligaciones relativas a los criterios de selección mediante la aplicación de criterios objetivos vinculados al objeto de la concesión.

b) Someter la adjudicación a los principios de transparencia, no discriminación e igualdad de trato, si bien a diferencia de la Directiva de contratación pública, no contiene un catálogo fijo de procedimientos de adjudicación, lo que permitirá a los Estados miembros mantener los sistemas nacionales tradicionales.

c) Establecer determinadas previsiones en materia de modificación, subcontratación y resolución de las concesiones de obras y servicios.

d) Extender el ámbito de aplicación de las Directivas sobre recursos ${ }^{40}$ a los contratos de concesión que superen el umbral comunitario con el fin de garantizar la posibilidad de impugnación de la decisión de adjudicación.

\section{Concepto de concesión, ámbito de aplicación y exclusiones}

En relación al concepto de concesión, la Directiva especifica que se trata de contratos celebrados a título onerosos por uno o más poderes o entidades adjudicadores que confían la ejecución de obras o la prestación y gestión de servicios a uno o más operadores económicos. Y cuyo objeto contractual consiste en el derecho a explotar la obra o el servicio o este mismo derecho junto a un pago. Entiende la Directiva por «concesión de servicios» el contrato celebrado a título oneroso por escrito, en virtud del cual uno o más poderes o entidades adjudicadores confían la prestación y la gestión de servicios distintos de la ejecución de obras a uno o más operadores económicos, cuya contrapartida es bien el derecho a explotar los servicios objeto del contrato únicamente, o este mismo derecho en conjunción con un pago.

La adjudicación de la concesión de servicios ha de implicar siempre la transferencia al concesionario de un riesgo operacional de carácter económico en la explotación de dicho servicio abarcando el riesgo de demanda o el de suministro, o ambos ${ }^{41}$. Se considerará que el concesionario asume un riesgo operacional cuando no esté garantizado que, en condiciones normales de funcionamiento, vaya a recuperar las inversiones realizadas ni a cubrir los costes que haya contraído para explotar las obras o los servicios que sean objeto de la concesión. La parte de los riesgos transferidos al concesionario supondrá una exposición real a las incertidumbres del mercado que implique que cualquier pérdida potencial estimada en que incurra el concesionario no es meramente nominal o desdeñable.

Quedan sometidas al ámbito de aplicación de la Directiva las concesiones de servicio que superen el umbral económico de 5.186.00 euros incluidos en el anexo II. Valor que será reflejo del interés transfronterizo de las

los anuncios de concesión, de adjudicación y de modificación, con indicación de su contenido, medios de remisión y plazos. En cambio, no contempla disposiciones relativas a los procedimientos de adjudicación (denominación, tipología, requisitos, plazos, etc.), sólo determinados requisitos genéricos, aplicables a la estructura del procedimiento que en cada caso se aplique.

38 "La presente Directiva no debe menoscabar en modo alguno la libertad de los Estados miembros y de las autoridades públicas para decidir el suministro directo de obras o servicios al público o la externalización de tal suministro delegándolo en terceros"

39 Especifica el considerando 5 de la Directiva que los Estados miembros y las autoridades públicas deberían continuar siendo libres para definir y especificar las características de los servicios que hayan de prestarse, incluidas las eventuales condiciones relativas a la calidad o el precio, de conformidad con el Derecho de la Unión, con el fin de lograr sus objetivos de interés público

40 Directivas 89/665/CEE y 92/13/CEE.

41 Especifica la Directiva que sus disposiciones no deben aplicarse a los contratos en los que el contratista reciba su retribución de acuerdo con tarifas reglamentadas calculadas de manera que cubran la totalidad de los costes e inversiones que este haya soportado para prestar el servicio (Considerando 17). 
concesiones para los operadores económicos situados en Estados miembros que no sean los del poder o la entidad adjudicadora $^{42}$. Cuando la concesión se adjudique en forma de lotes separados deberá tenerse en cuenta el valor total estimado de todos los lotes y cuando el valor acumulado de los lotes iguale o supere el umbral establecido se aplicará la Directiva a la adjudicación de cada lote.

La duración de las concesiones se calculará en función del servicio concedido. Para las concesiones que duren más de cinco años, la duración máxima no podrá exceder del tiempo que se calcule razonable para que el concesionario recupere las inversiones realizadas para la explotación de la obra o servicio, junto con un rendimiento del capital invertido (artículo 18).

\section{Exclusiones}

Los artículos 10 a 17 de la Directiva establecen un amplio listado de excepciones a su ámbito de aplicación, especificando que quedan fuera de su regulación, además de determinados servicios de transporte aéreo, del ámbito de la defensa y seguridad, y de las comunicaciones electrónicas, las siguientes actividades:

- Los juegos de azar y apuestas;

- Las concesiones relativas a la explotación de loterías

- El servicio público de agua potable, en concreto las concesiones de obras y servicios para suministrar o explotar redes fijas destinadas a prestar un servicio público relacionado con la producción, transporte o distribución de agua potable ${ }^{43}$

- Las concesiones formalizadas con arreglo a procedimientos de contratación en el marco de acuerdos internacionales.

- Los servicios de carácter social, sanitario o educativo ${ }^{44}$. Estos servicios se prestan en el marco de un contexto particular que varía mucho según el Estado miembro de que se trate debido a la existencia de diferentes tradiciones culturales.

- las relaciones entre autoridades públicas, las denominadas relaciones in house. Se trata de concesiones adjudicadas por un poder o entidad adjudicadora a otra persona jurídica de Derecho privado o de Derecho público cuando concurran todas las condiciones siguientes:

1. Que dicho poder o entidad adjudicadora ejerza sobre la persona jurídica un control análogo al que ejerce sobre sus propios servicios. Es decir, cuando el poder o entidad adjudicadora influya de forma decisiva tanto en los objetivos estratégicos como en las decisiones fundamentales de la persona jurídica controlada. Ese control podrá ser ejercido conjuntamente con otros poderes o entidades adjudicadoras.

2. Que más del $80 \%$ de las actividades que lleve a cabo la persona jurídica lo haga en el ejercicio de los cometidos encomendados por el poder o entidad adjudicadora.

3. Que no exista participación directa de capital privado en la persona jurídica controlada, con la excepción de las formas de participación de capital privado impuestas por las disposiciones de la legislación nacional, de conformidad con los Tratados, sin capacidad de control mayoritario ni minoritario, y que no ejerza una influencia decisiva sobre la persona jurídica controlada45.

42 El cálculo debe referirse al volumen de negocios total de la empresa concesionaria contrapartida de las obras y servicios objeto de la concesión, calculado por el poder o la entidad adjudicador, excluido el IVA, durante la duración del contrato.

43 En el sector del agua, las concesiones están sujetas a menudo a mecanismos específicos y complejos que requieren una consideración especial debido a la importancia del agua como bien público de valor fundamental para todos los ciudadanos de la Unión. Las características especiales de dichos mecanismos justifican la exclusión del sector del agua del ámbito de aplicación de la presente Directiva. La exclusión incluye las concesiones de obras y servicios para suministrar o explotar redes fijas destinadas a prestar un servicio al público en relación con la producción, el transporte o la distribución de agua potable o a suministrar agua potable a dichas redes (considerando

44 No obstante, la Directiva señala que debe establecerse un régimen específico para la concesión de estos servicios en el que se incluya la obligación de publicar, en el caso de concesiones de un valor igual o superior a los umbrales establecidos, un anuncio de información previa y un anuncio de adjudicación, con el objetivo de informar a los posibles licitadores de las posibilidades económicas que se les ofrecen, y a todas las partes interesadas del número y tipo de contratos adjudicados.

45 Concreta el considerando 46 de la Directiva que la excepción no debe extenderse a situaciones en las que exista participación directa de un operador económico privado en el capital de la persona jurídica controlada, ya que en ese caso la adjudicación de la concesión sin un procedimiento competitivo otorgaría al operador económico privado con presencia en el capital de la persona jurídica controlada una ventaja indebida respecto a sus competidores. No obstante, dadas las características particulares de los órganos públicos con afiliación obligatoria, tales como las organizaciones encargadas de la gestión o la prestación de determinados servicios públicos, esto no se debe aplicar cuando la participación de determinados operadores económicos privados en el capital de la persona jurídica controlada es obligatoria en virtud de una 
Se trata de supuestos de concesiones adjudicadas por un poder o entidad adjudicadora a otra persona jurídica cuando dicho poder ejerza sobre ésta un control análogo al que ejerce sobre sus propios servicios, exigiendo que la persona jurídica controlada no cuente con participación privada.

\section{Principios generales y garantías procedimentales}

El poder o entidad adjudicador tendrá libertad para poder organizar el procedimiento conducente a la elección del concesionario. No obstante, el procedimiento de adjudicación de la concesión deberá respetar los principios de igualdad de trato y no discriminación, transparencia, y proporcionalidad ${ }^{46}$. En particular, durante el procedimiento de adjudicación, el poder adjudicador o la entidad adjudicadora no podrá facilitar información de forma discriminatoria que pueda dar ventajas a determinados candidatos o licitadores con respecto a otros. Exigiendo el artículo 31 que los poderes y entidades adjudicadores que deseen adjudicar una concesión darán a conocer su propósito por medio de un anuncio de concesión que contendrá la información que figura en el anexo $\mathrm{V}$ y, si procede, cualquier otra información que el poder o entidad considere conveniente, con arreglo al formato de los formularios normalizados. Cuando se trate de una concesión de servicios sociales u otros servicios específicos de los enumerados en el anexo IV, los poderes o entidades adjudicadores que deseen adjudicar una concesión darán a conocer su intención a través de la publicación de un anuncio de de información previa ${ }^{47}$.

Quedan obligados los poderes adjudicadores a tomar las medidas adecuadas para luchar contra el fraude, el favoritismo y la corrupción y prevenir, detectar y solucionar de modo efectivo los conflictos de intereses ${ }^{48}$ que puedan surgir en los procedimientos de adjudicación de concesiones a fin de evitar cualquier distorsión de la competencia y garantizar la transparencia del procedimiento de adjudicación y la igualdad de trato de todos los candidatos y licitadores.

Las concesiones se otorgarán en función de los criterios de adjudicación establecidos por el poder o entidad adjudicador de conformidad con el artículo 41, siempre que se cumplan las siguientes condiciones:

a) que el licitador cumpla los requisitos consignados por el poder o entidad adjudicador, en particular con las condiciones y características técnicas, físicas, funcionales y jurídicas

b) que el licitador cumpla las condiciones de participación mencionadas en el artículo 38, apartado 1 de la Directiva 49

c) que el licitador no esté excluido de participar en el procedimiento de adjudicación en virtud del artículo 38, apartados 4 a 7, sin perjuicio de lo dispuesto en el artículo 38, apartado 9.

Los criterios de adjudicación de las concesiones han de ser objetivos y deberán cumplir con los principios de igualdad de trato y no discriminación, transparencia, y proporcionalidad, garantizando la evaluación de las ofertas en unas condiciones de competencia efectiva tales que se pueda determinar la ventaja económica global para el poder adjudicador o la entidad adjudicadora. Los criterios estarán vinculados al objeto de la concesión y no conferirán al órgano de contratación una libertad de elección ilimitada. Podrán incluir, entre otros, criterios

disposición de la legislación nacional conforme a los Tratados, siempre que dicha participación no permita controlar ni bloquear a la persona jurídica controlada y no confiera una influencia decisiva en las decisiones de dicha persona. Debe aclararse asimismo que el elemento decisivo es únicamente la participación privada directa en la persona jurídica controlada.

46 Principios establecidos en el artículo 3 de la Directiva donde se especifica que los poderes y entidades adjudicadores darán a los operadores económicos un trato igualitario y no discriminatorio y actuarán de forma transparente y proporcionada. El procedimiento de adjudicación de la concesión, incluida la estimación del valor, no será concebido con la intención de excluirlo del ámbito de aplicación de la Directiva ni de favorecer o perjudicar indebidamente a determinados operadores económicos o determinadas obras, suministros o servicios. Y tendrá como objetivo garantizar la transparencia de la adjudicación y de la ejecución del contrato, respetando al mismo tiempo la confidencialidad de las ofertas.

47 Estos anuncios contendrán la información recogida en el anexo VI.

48 Conflicto de intereses que abarcará al menos cualquier situación en la que los miembros del personal del poder o entidad adjudicador que participen en el desarrollo del procedimiento de adjudicación de una concesión o puedan influir en el resultado de dicho procedimiento tengan, directa o indirectamente, un interés financiero, económico o particular que pudiera parecer que compromete su imparcialidad e independencia en el contexto del procedimiento de adjudicación de la concesión.

49 Donde se señala que los poderes y entidades adjudicadores deberán comprobar las condiciones de participación relativas a la capacidad profesional y técnica, la solvencia financiera y económica de los licitadores o candidatos, sobre la base de las declaraciones de los mismos, la referencia o referencias que se presenten como prueba de conformidad con el requisitos especificados en el anuncio de licitación, que deberán ser no discriminatorias y proporcionales al objeto de la concesión. Las condiciones de participación guardarán una relación y una proporción con la necesidad de garantizar la capacidad del concesionario de ejecutar la concesión, teniendo en cuenta el objeto de la concesión y la finalidad de garantizar una competencia real 
medioambientales, sociales o relacionados con la innovación (artículo 41 de la Directiva).

Adjudicada la concesión el poder o entidad adjudicador informará sin demora a los candidatos y los licitadores de las decisiones tomadas en relación con la adjudicación de la concesión, incluidos los nombres de los licitadores seleccionados, las razones por las que se haya desestimado su solicitud de participación o su oferta, así como las razones por las que, en su caso, haya decidido no adjudicar un contrato que había sido anunciado o reiniciar el procedimiento.

Para garantizar que durante la ejecución de contratos de concesión los operadores económicos cumplen con las obligaciones establecidas por la legislación en materia medioambiental, laboral y social ${ }^{50}$, los Estados miembros están obligados a adoptar las medidas pertinentes para hacer efectivas dichas obligaciones.

\section{El riesgo del concesionario como elemento central de la concesión: riesgo operacional de carácter económico}

Incide la Directiva que la característica principal de una concesión, el derecho de explotar el servicio, implica siempre la transferencia al concesionario de un riesgo operacional de carácter económico que puede suponer que el concesionario no recupere las inversiones realizadas ni cubra los costes que haya sufragado en su explotación en condiciones normales de funcionamiento, aunque una parte del riesgo lo asuma el poder o entidad adjudicador ${ }^{51}$.

La distribución de riesgos recae por tanto sobre el concepto de "riesgo operacional de carácter económico" que incluye el riesgo de demanda o el de suministro, o ambos ${ }^{52}$. El riesgo operacional debe derivarse de factores que escapan al control de las partes. Los riesgos vinculados a una mala gestión, a los incumplimientos de contrato por parte del operador económico o a situaciones de fuerza mayor, no son determinantes a efectos de la calificación como concesión, ya que tales riesgos son inherentes a cualquier tipo de contrato, tanto si es un contrato público como si es una concesión. Debe entenderse como riesgo operacional el riesgo de exposición a las incertidumbres del mercado, que puede consistir en un riesgo de demanda o en un riesgo de suministro, o de ambos a la vez.

Con ello recoge la Directiva la jurisprudencia consolidada del TJUE sobre esta materia. La STJUE de 10 de marzo de 2011, Asunto C-274/09, incluye en "el riesgo de explotación económica del servicio":

-La exposición a las incertidumbres del mercado,

-La competencia de otros operadores,

-Los desajuste entre la oferta y la demanda de los servicios,

-La insolvencia de los deudores por los servicios prestados,

-Que los ingresos no cubran íntegramente los gastos de explotación, y

-La responsabilidad por un perjuicio causado por una irregularidad en la prestación del servicio.

El adjetivo “operacional de carácter económico" que utiliza la Directiva permite excluir la hipótesis de que el concesionario deba soportar todos los riesgos que puedan presentarse en el desarrollo del contrato ${ }^{53}$. El artículo 18 establece que la concesión no podrá exceder el tiempo que se calcule razonable para que el concesionario recupere las inversiones realizadas para la explotación de las obras o servicios, junto con un rendimiento sobre el capital invertido, teniendo en cuenta las inversiones necesarias para alcanzar los objetivos contractuales específicos. Ello explica que la Directiva contemple el riesgo imprevisible al regular la modificación de la concesión, permitiendo dicha modificación si la necesidad deriva de circunstancias que el adjudicador diligente no podía prever, siempre que la modificación no altere el carácter global de la concesión y el posible aumento de valor no supere el 50\% del valor de la concesión original adjudicada por un poder adjudicador. No obstante, el artículo 43.4 apartado b prohíbe de forma expresa la modificación que altere el equilibrio económico de la concesión a favor del concesionario cuando no estaba previsto en la concesión inicial.

50 Entre estas obligaciones se incluyen las establecidas por la legislación de la Unión Europea, la legislación nacional, los convenios colectivos y las disposiciones de Derecho Internacional en materia medioambiental, social y laboral. El Anexo X de la Directiva contiene la lista de convenios internacionales en el ámbito social y medioambiental a que se refiere el artículo 30 apartado 3 de la Directiva.

51 La regulación de la adjudicación de concesiones mediante normas específicas no estaría justificada si el poder adjudicador o la entidad adjudicadora aliviase al contratista de cualquier pérdida potencial garantizando unos ingresos mínimos iguales o superiores a los costes que el contratista deba asumir en relación con la ejecución del contrato. Tampoco entra en el ámbito de aplicación de la Directiva la simple financiación de una actividad, que a menudo va ligada a la obligación de reembolsar las cantidades que no se hubieran destinado a los fines previstos.

52 El primer borrador de la propuesta de directiva incluía el concepto de riesgo operacional sustancial (ROS) que implicaba mayor intensidad en la transferencia de riesgo.

53 Interpretación que guarda sintonía con la jurisprudencia del TJUE al proclamar los rasgos fundamentales de estos contratos y con lo expresado por la propia Comisión Europea en la Comunicación interpretativa del año 2000 sobre contratos de concesión. 
Un exceso de riesgo para el concesionario podría suponer un encarecimiento excesivo del precio exigido por el sector privado para retribuir el riesgo asumido, o, en el peor de los casos, la no viabilidad financiera del proyecto. Por el contrario, un exceso de riesgos soportado por la Administración supondría elevar el nivel de endeudamiento afectando directamente a la estabilidad presupuestaria. Es necesario por ello realizar un previo estudio de viabilidad en la distribución de riesgos para que los asuma la parte más capacitada y pueda, consecuentemente, minimizarlos. El éxito de la concesión dependerá en gran medida de una adecuada asignación de riesgos entre los diferentes agentes que forman parte en el proceso.

\section{Modificación de la concesión}

Establece el artículo 43 de la Directiva un principio general: toda modificación sustancial de las disposiciones de una concesión durante su periodo de vigencia será considerada una nueva adjudicación y conllevará un nuevo procedimiento de ejecución. Se considera sustancial una modificación cuando tenga como resultado una concesión materialmente diferente, en cuanto a su carácter, de la celebrada en un principio, o cuando se cumpla una de las condiciones siguientes:

1. Que la modificación introduzca condiciones que, de haber figurado en el procedimiento inicial de adjudicación de la concesión, habrían permitido la selección de solicitantes distintos de los seleccionados inicialmente o la aceptación de una oferta distinta a la aceptada inicialmente, o habrían atraído a más participantes en el procedimiento de adjudicación de la concesión.

2. Que la modificación altere el equilibrio económico de la concesión a favor del concesionario en un modo que no estaba previsto en la concesión inicial.

3. Que la modificación amplíe considerablemente el ámbito de la concesión

4. Cuando un nuevo concesionario sustituya a aquel al que el poder adjudicador o la entidad adjudicadora había adjudicado inicialmente la concesión. Siempre que se produzca la cesión o sustitución del concesionario por causas distintas a las previstas en el artículo 43.1 letra d) ${ }^{54}$.

En estos casos será preceptivo iniciar un nuevo procedimiento de adjudicación.

No obstante, no será preceptivo iniciar un nuevo procedimiento en los siguientes casos:

a) Cuando las modificaciones, con independencia de su valor pecuniario, estuvieran ya previstas en la documentación inicial de la concesión, en cláusulas de revisión claras, precisas e inequívocas, entre las que puede haber cláusulas de revisión de precios. Estas cláusulas determinarán el alcance y la naturaleza de las posibles modificaciones u opciones, así como las condiciones en que se puede recurrir a ellas. No contendrán modificaciones u opciones que puedan alterar el carácter global de la concesión.

b) Para servicios adicionales, a cargo del concesionario original, que resulten necesarios y que no estuviesen incluidos en la concesión original, cuando un cambio de concesionario no sea factible por razones económicas o técnicas ${ }^{55}$, genere inconvenientes significativos o un aumento sustancial de costes para el poder o entidad adjudicador.

No obstante, en el caso de concesiones adjudicadas por el poder adjudicador a efectos del ejercicio de una actividad distinta de las enumeradas en el anexo III de la Directiva, el posible aumento de valor no podrá superar el $50 \%$ del valor de la concesión original. En caso de que se apliquen varias modificaciones sucesivas, esta limitación se aplicará al valor de cada una de ellas. Estas modificaciones consecutivas no podrán tener por objetivo el de eludir la Directiva;

c) Cuando se cumplan todas las condiciones siguientes:

$1^{a}$ ) Que la necesidad de modificación se derive de circunstancias que un poder o entidad adjudicador diligente no podía prever;

$2^{\mathrm{a}}$ ) Que la modificación no altere el carácter global de la concesión;

54 Donde se establece que podrán modificarse las concesiones sin necesidad de iniciar un nuevo procedimiento de concesión cuando un nuevo concesionario sustituya al designado en un principio como consecuencia de una opción o cláusula de revisión clara, precisa e inequívoca, entre las que puede haber cláusulas de revisión de precios u opciones inequívocas; o a raíz de una reestructuración empresarial, en particular por absorción, fusión, adquisición o insolvencia, por otro operador económico que cumpla los criterios de selección cualitativa establecidos inicialmente, siempre que ello no implique otras modificaciones sustanciales del contrato ni tenga por objeto eludir la aplicación de la Directiva. O bien ante la asunción por el propio poder o entidad adjudicador de las obligaciones del concesionario principal para con sus subcontratistas, siempre que esta posibilidad esté prevista en la legislación nacional.

55 Razones de intercambiabilidad o interoperatividad con el equipo existente, servicios o instalaciones adquiridos en el marco de la concesión inicial 
$3^{\mathrm{a}}$ ) En el caso de las concesiones adjudicadas por el poder adjudicador a efectos del ejercicio de una actividad distinta de las enumeradas en el anexo II, el posible aumento de valor no podrá superar el $50 \%$ del valor de la concesión original. En caso de que se apliquen varias modificaciones sucesivas, esta limitación se aplicará al valor de cada una de ellas. Estas modificaciones consecutivas no podrán tener por objetivo el de eludir lo dispuesto en la presente Directiva;

d) Cuando un nuevo concesionario sustituya al designado en un principio como adjudicatario como consecuencia de una opción o cláusula de revisión clara, precisa e inequívoca, entre las que puede haber cláusulas de revisión de precios; o como consecuencia de la sucesión total o parcial del concesionario inicial, a raíz de una reestructuración empresarial, en particular por absorción, fusión, adquisición o insolvencia, por otro operador económico que cumpla los criterios de selección cualitativa establecidos inicialmente, siempre que ello no implique otras modificaciones sustanciales del contrato ni tenga por objeto eludir la aplicación de la presente Directiva; o cuando se produzca la asunción por el propio poder o entidad adjudicador de las obligaciones del concesionario principal para con sus subcontratistas, siempre que esta posibilidad esté prevista en la legislación nacional.

e) Cuando las modificaciones, con independencia de su valor, no sean consideradas sustanciales.

Las modificaciones producidas como consecuencia de adicionar servicios a la concesión, o cuando se cumplan todas las condiciones establecidas en el artículo 4.1 apartado c (imprevisibilidad) deberán publicarse en el Diario Oficial de la Unión Europea incluyendo la información establecida en el anexo XI y se publicará de acuerdo con lo dispuesto en el artículo 33 de la Directiva.

Los poderes adjudicadores y entidades adjudicadoras pueden encontrarse con circunstancias exteriores que no podían prever cuando adjudicaron la concesión, en particular si la ejecución de la concesión se extiende durante un largo periodo de tiempo. En este caso se necesita un cierto grado de flexibilidad para adaptar la concesión a las nuevas circunstancias sin necesidad de un nuevo procedimiento de adjudicación. El concepto de circunstancias imprevisibles hace referencia a aquellas circunstancias que no podrían haberse previsto aunque el poder adjudicador o la entidad adjudicadora hubiera preparado con razonable diligencia la adjudicación inicial, teniendo en cuenta los medios a su disposición, la naturaleza y las características del proyecto concreto, las buenas prácticas en el ámbito de que se trate y la necesidad de garantizar una relación adecuada entre los recursos empleados en la preparación de la adjudicación y su valor previsible. Ahora bien, esto no puede aplicarse en los casos en que la modificación implique una alteración de la naturaleza del conjunto de la concesión, por ejemplo si se sustituyen las obras que deban ejecutarse o los servicios que deban prestarse por otros diferentes o si se modifica de forma fundamental el tipo de la concesión ya que, en ese caso, puede presumirse una hipotética influencia en los resultados.

Tampoco considera la Directiva modificación sustancial una modificación cuando su valor no supere el límite de aplicación de la Directiva (concesiones de un valor igual o superior a 5186000 euros), ni exceda un 10\% del valor inicial de la concesión, con las previsiones de no alterar el carácter global de la concesión y de tener en cuenta para este cálculo las sucesivas modificaciones. Cuando se efectúen varias modificaciones sucesivas, el valor se calculará sobre la base del valor neto acumulado de las sucesivas modificaciones.

Como vemos el legislador comunitario distingue entre "modificación" y "modificación sustancial”. Esta última alude a supuestos en los que la revisión pretendida es de tal magnitud que termina desdibujando por completo el contrato original para dar lugar a uno distinto.

No serán consideradas modificaciones sustanciales las modificaciones que hayan sido previstas en los documentos de la concesión a través de cláusulas u opciones de revisión claras, precisas e inequívocas. Estas cláusulas determinarán el alcance y la naturaleza de las posibles modificaciones u opciones, así como las condiciones en que se puede recurrir a ellas, y no podrán alterar el carácter global de la concesión.

La sustitución del concesionario se considerará una modificación sustancial, salvo que dicha sucesión se deba a razones de reestructuración de empresas o de insolvencia, o a la cláusula contractual a la que se obliga otro operador económico que se ajusta a los criterios de selección cualitativa establecidos originalmente, siempre que ello no implique otras modificaciones sustanciales de la concesión y que su objetivo no sea soslayar la aplicación de la normativa sobre concesiones.

No obstante, una modificación sustancial no conllevará un nuevo procedimiento de adjudicación cuando concurran todas las condiciones siguientes: a) que la necesidad de modificación se derive de circunstancias que un poder adjudicador o una entidad adjudicadora diligente no podía prever.. b) que la modificación no altere el carácter global de la concesión; c) en el caso de concesiones adjudicadas por poderes adjudicadores, que el 
aumento del precio no sea superior al 50 \% del valor de la concesión original. Previsión que deja abierta la puerta a la aplicación de la teoría del riesgo imprevisible ${ }^{56}$. El límite del 50\% del valor de la concesión original es aplicable únicamente a las concesiones adjudicadas por poderes adjudicadores, no para las adjudicadas por entidades adjudicadoras ${ }^{57}$.

\section{Subcontratación}

No cabe duda que la subcontratación permite la participación de las PYMEs en la adjudicación de contratos de concesión y por tanto favorece su desarrollo económico, sin embargo, se han producido con demasiada frecuencia casos alarmantes, donde la práctica de la cadena de subcontratación ha dado lugar a casos de explotación y a contratos públicos de menor calidad. En consecuencia, la Directiva propone la introducción del principio de responsabilidad en toda la cadena de subcontratación, para que en todas las etapas del proceso el contratista principal y el subcontratista tengan la responsabilidad de respetar los derechos fundamentales y el cumpliendo de la legislación laboral.

También ayudarán a evitar que la subcontratación incumpla la legislación laboral las disposiciones relativas a las ofertas denominadas temerarias o anormalmente bajas previstas en la Directiva sobre contratación pública.

Para que los Estados miembros adopten las medidas pertinentes para garantizar que en la ejecución de contratos de concesión los concesionarios cumplan con las obligaciones establecidas por la legislación en materia medioambiental, laboral y social ${ }^{58}$, la Directiva exige que las autoridades nacionales competentes aseguren mediante la adopción de las medidas adecuadas que los subcontratistas cumplan dichas obligaciones.

Tras la adjudicación de la concesión y, a más tardar, cuando se inicie la ejecución de ésta, el poder o entidad adjudicador exigirá al concesionario que le comunique el nombre, los datos de contacto y los representantes legales de los subcontratistas que intervengan en las obras o servicios en cuestión, siempre que se conozcan en ese momento. Exigiéndole al contratista principal que le notifique cualquier modificación que sufra esta información durante el transcurso de la concesión, y toda la información necesaria sobre los nuevos subcontratistas a los que asocie ulteriormente a la obra o servicio en cuestión.

En los documentos relativos a la concesión, el poder adjudicador o la entidad adjudicadora podrá pedir al licitador que mencione en la oferta la parte de la concesión que se proponga subcontratar a terceros, así como los subcontratistas propuestos, sin prejuzgar con ello la responsabilidad del concesionario principal.

Los poderes adjudicadores y las entidades adjudicadoras, por decisión propia o por requerimiento de los Estados miembros, podrán verificar, de conformidad con el artículo 38, apartados 4 a 10, si concurren motivos para excluir a algún subcontratista. En tales casos, el poder adjudicador o la entidad adjudicadora deberá exigir que el concesionario sustituya al subcontratista que haya incurrido, según las conclusiones de la verificación, en motivos de exclusión obligatoria. No obstante, los Estados miembros podrán limitar los supuestos de aplicación de tales medidas respecto de determinados tipos de contrato o determinadas categorías de poderes adjudicadores, entidades adjudicadoras u operadores económicos o a partir de ciertos importes.

\section{Resolución de la concesión}

En ocasiones, los poderes adjudicadores y entidades adjudicadoras deben afrontar circunstancias que exigen la extinción anticipada de la concesión. Por consiguiente, los Estados miembros deben asegurarse de que los poderes adjudicadores y entidades adjudicadoras tengan la posibilidad, con arreglo a condiciones determinadas por la legislación nacional aplicable, de poner fin a una concesión durante su periodo de vigencia, siempre que así lo exija el Derecho de la Unión.

El artículo 44 de la Directiva determina que los Estados miembros se asegurarán de que los poderes y entidades adjudicadores tengan la posibilidad, con arreglo a condiciones determinadas por la legislación nacional aplicable, de poner fin a una concesión durante su periodo de vigencia, siempre que se cumpla alguna de las condiciones siguientes:

56 Se consideran circunstancias imprevisibles aquellas circunstancias que no podían predecirse a pesar de la diligente preparación del procedimiento original, teniendo en cuenta los recursos, naturaleza y características del proyecto específico, las buenas prácticas del ámbito en cuestión y la necesidad de asegurar una proporción adecuada entre los recursos destinados a la preparación de la adjudicación y su valor previsto

57 La posibilidad de modificar la concesión hasta el importe de la mitad de su valor original exige que concurran las tres condiciones previstas en el artículo 43.1 apartado c) de la Directiva: imprevisión, que no afecte al carácter global de la concesión y el precio.

58 Se refiere el artículo 30.3 de la Directiva al cumplimiento de las obligaciones derivadas de la legislación de la Unión Europea, la legislación nacional, los convenios colectivos, y las disposiciones de Derecho internacional en materia medioambiental, social y laboral enumeradas en el anexo $\mathrm{X}$ 
1. que una modificación de la concesión suponga una nueva adjudicación, de conformidad con el artículo 43;

2. que el contratante se encuentre, en el momento de la adjudicación del contrato, en una de las situaciones contempladas en el artículo 38, apartado 4, de la Directiva y, por lo tanto, hubiere debido ser excluido del procedimiento de adjudicación de la concesión;

3. que el Tribunal de Justicia de la Unión Europea dictamine, en un procedimiento conforme con el artículo 258 del TFUE, que un Estado miembro ha incumplido sus obligaciones con arreglo a los Tratados debido a que un poder adjudicador o entidad adjudicadora de dicho Estado miembro ha adjudicado una concesión sin ajustarse a las obligaciones que le imponen los Tratados o la presente Directiva.

El primer supuesto de resolución contemplado en el artículo 44 de la Directiva tiene lugar cuando la revisión de la concesión suponga o encubra una modificación sustancial, es decir, cuando suponga una nueva adjudicación, de conformidad con lo establecido en el artículo 43.4 de la Directiva.

El segundo supuesto de resolución se refiere a que el contratante se encuentre incurso en alguna de las prohibiciones de contratar que contempla el artículo 38.4 de la Directiva por ser objeto de una condena mediante sentencia firme por participación en una organización delictiva ${ }^{59}$, corrupción ${ }^{60}$, fraude ${ }^{61}$, delito de terrorismo o delito ligado a actividades terroristas ${ }^{62}$, blanqueo de capitales o financiación del terrorismo ${ }^{63}$, trabajo infantil y otras formas de trata de seres humanos ${ }^{64}$.

El último supuesto de resolución tiene lugar cuando el TJUE dictamine, en un procedimiento abierto por la Comisión ${ }^{65}$ que un Estado miembro ha incumplido sus obligaciones con arreglo a los Tratados debido a que un poder o entidad adjudicadora de dicho Estado miembro ha adjudicado una concesión sin ajustarse a las obligaciones que le imponen el Derecho comunitario. Es decir, la sentencia del TJUE que declare un incumplimiento por parte de un Estado miembro posee ex lege además de carácter declarativo y la consecuente obligación de acatamiento ${ }^{66}$, un efecto resolutorio directo sobre el respectivo contrato de concesión.

El considerando 80 de la Directiva incluye el término rescisión en lugar del de resolución y esta utilización terminológica puede implicar en nuestro país cierta confusión e inseguridad debido a su diferente concepto, contenido, efectos y régimen jurídico. La rescisión del contrato y la resolución son dos modalidades de ineficacia contractual encuadradas dentro de la teoría general de los actos y negocios jurídicos pero sus efectos y requisitos son distintos.

La rescisión obra en virtud de ley y no en base a la voluntad de las partes contratantes67. Sus requisitos son:

- contrato inicialmente valido;

- existencia posterior de una lesión o perjuicio para una de las partes contratantes (o para un tercero,

59 Tal como se define en el artículo 2 de la Decisión marco 2008/841/JAI, de 24 de octubre de 2008, relativa a la lucha contra la delincuencia organizada.

60 tal como se define en el artículo 3 del Convenio relativo a la lucha contra los actos de corrupción en los que estén implicados funcionarios de las Comunidades Europeas o de los Estados miembros de la Unión Europea, y en el artículo 2, apartado 1, de la Decisión marco 2003/568/JAl, de 22 de julio así como la corrupción definida en la legislación nacional del poder o entidad adjudicador o del operador económico.

61 A tenor del artículo 1 del Convenio relativo a la protección de los intereses financieros de las Comunidades Europeas

62 Según se definen, respectivamente, en los artículos 1 y 3 de la Decisión marco 2002/475/JAI, de 13 de junio, o inducción, complicidad o tentativa, tal como se contemplan en el artículo 4 de la citada Decisión marco;

63 Tal como se definen en el artículo 1 de la Directiva 2005/60/CE, de 26 de octubre, relativa a la prevención de la utilización del sistema financiero para el blanqueo de capitales y para la financiación del terrorismo.

64 tal como se definen en el artículo 2 de la Directiva 2011/36/UE, de 5 de abril de 2011, relativa a la prevención y lucha contra la trata de seres humanos y a la protección de las víctimas y por la que se sustituye la Decisión marco 2002/629/JAl.

65 Conforme al artículo 258 del TFUE, si la Comisión estimare que un Estado miembro ha incumplido una de las obligaciones que le incumben en virtud de los Tratados, emitirá un dictamen motivado al respecto, después de haber ofrecido a dicho Estado la posibilidad de presentar sus observaciones. Si el Estado de que se trate no se atuviere a este dictamen en el plazo determinado por la Comisión, ésta podrá recurrir al Tribunal de Justicia de la Unión Europea. Cuando la Comisión presente un recurso ante el Tribunal de Justicia de la Unión Europea en virtud del artículo 258 TFUE por considerar que el Estado miembro afectado ha incumplido la obligación de informar sobre las medidas de transposición de una directiva adoptada con arreglo a un procedimiento legislativo, podrá, si lo considera oportuno, indicar el importe de la suma a tanto alzado o de la multa coercitiva que deba ser pagada por dicho Estado y que considere adaptado a las circunstancias.

66 Si el Tribunal de Justicia de la Unión Europea declarare que un Estado miembro ha incumplido una de las obligaciones que le incumben en virtud de los Tratados, dicho Estado estará obligado a adoptar las medidas necesarias para la ejecución de la sentencia del Tribunal. Y si el Tribunal comprueba la existencia del incumplimiento, podrá imponer al Estado miembro afectado el pago de una suma a tanto alzado o de una multa coercitiva dentro del límite del importe indicado por la Comisión. La obligación de pago surtirá efecto en la fecha fijada por el Tribunal en la sentencia (artículo 260.1 TFUE).

67 La rescisión es la causa de extinción de un contrato inicialmente válido pero que posteriormente es declarado ineficaz por sus efectos lesivos para una de las partes o para un tercero. El artículo 1290 del Código Civil establece que los contratos válidamente celebrados pueden rescindirse en los casos establecidos por la ley. 
acreedores de estas);

- carácter subsidiario ante la inexistencia de otro medio para paliar la lesión;

- sus causas están taxadas en el artículo 1291 del Código Civil ${ }^{68}$.

- La acción para pedir la rescisión dura cuatro años.

La rescisión supone que se anule el contrato (nunca debió existir ni desplegar sus efectos), la puede instar un tercero no contratante que se considere lesionado por el contrato, existe un plazo predeterminado para solicitarla (4 años), es siempre acción subsidiaria (es decir, el perjudicado no cuenta con otra vía para resarcirse), y sólo cabe por las causas contempladas en la ley69. Comporta la devolución de las cosas objeto del contrato con sus frutos, y del precio con sus intereses, de modo que no procederá cuando las cosas a devolver estén legalmente en poder de un tercero de buena fe. En ese caso procedería la indemnización por el causante de la lesión.

La resolución se diferencia de la rescisión en que no tiene carácter subsidiario; carece de regulación sistemática en el Código Civil aunque si existen referencias expresas a la misma70; puede solicitarse ante un incumplimiento por alguna de las partes; no tiene un plazo predeterminado para poder solicitarla; implica la extinción anticipada del contrato en un momento anterior al previsto inicialmente (el contrato existió y desplegó sus efectos), y sólo cabe ejercitarla entre las partes del contrato.

Por todo ello llama la atención la inclusión en algunas partes de la Directiva del término de rescisión en lugar del término más habitual en la normativa contractual pública de resolución del contrato. Las razones podemos encontrarlas en la diversidad de culturas jurídicas a las que se dirige la normativa comunitaria, es decir, en la búsqueda de homogeneización o armonización conceptual ante la variedad de ordenamientos jurídicos de los Estados miembros. También en que la normativa comunitaria es aséptica a la naturaleza jurídica del contrato, al incluir tanto al contrato privado como al contrato administrativo del sector público, y el término rescisión es más frecuente en el ámbito del sector privado ${ }^{71}$.

\section{CONCLUSIONES}

Teniendo en cuenta tal como señalan los artículos 6 y 7 que la Directiva sobre concesiones se aplicará a los contratos de concesión adjudicados por poderes ${ }^{72}$ y entidades adjudicadores y que el concepto de entidad adjudicadora incluye a las empresas públicas ${ }^{73}$ y a las entidades que no son poderes adjudicadores ni empresas públicas que operan con arreglo a derechos especiales o exclusivos otorgados por una autoridad competente de un Estado miembro ${ }^{74}$, el ámbito subjetivo de aplicación se extiende de forma muy amplia a entes, organismos

68 Concreta el artículo 1291 del C.c que son rescindibles:

-Los contratos que pudieren celebrar los tutores sin autorización judicial, siempre que las personas a quienes representan hayan sufrido lesión en más de la cuarta parte del valor de las cosas que hubieren sido objeto de aquéllos.

-Los celebrados en representación de los ausentes, siempre que éstos hayan sufrido la lesión a que se refiere el número anterior.

-Los celebrados en fraude de acreedores, cuando éstos no puedan de otro modo cobrar lo que se les deba.

-Los contratos que se refieran a cosas litigiosas, cuando hubiesen sido celebrados por el demandado sin conocimiento y aprobación de las partes litigantes o de la Autoridad judicial competente.

-Cualesquiera otros en que especialmente lo determine la ley.

Son también rescindibles los pagos hechos en estado de insolvencia por cuenta de obligaciones a cuyo cumplimiento no podía ser compelido el deudor al tiempo de hacerlos (artículo 1292 C.c).

69 La rescisión afecta a contratos que desde su inicio implican un daño o lesión a una de las partes. No se trata de cumplir o no el contrato, es que el mismo se ha celebrado en perjuicio de uno de ellos o de terceros (existe una especialidad, en fraude de acreedores, al celebrarse el contrato en perjuicio de un tercero).

70 Ejemplo, la condición resolutoria tacita del artículo 1124 Código Civil, la posibilidad de pactar la condición resolutoria contemplada en el artículo 1114 del mismo texto legal.

71 O por qué no, en una razón más peregrina, la falta de costumbre de la normativa contractual pública europea de entrar a regular las cuestiones relacionadas con las fases de ejecución y extinción del contrato.

72 Tienen la consideración de «poderes adjudicadores»: el Estado, las autoridades regionales o locales, los organismos de Derecho público y las asociaciones formadas por una o varias de tales autoridades o uno o varios de dichos organismos de Derecho público, distintos de aquellos que desarrollen alguna de las actividades recogidas en el anexo II y adjudiquen una concesión para la realización de una de esas actividades.

73 Considera la Directiva como empresa pública aquella empresa sobre la que los poderes adjudicadores puedan ejercer, directa o indirectamente, una influencia dominante por razón de propiedad o participación financiera o en virtud de las normas que la rigen. Se considerará que los poderes adjudicadores ejercen una influencia dominante, directa o indirectamente, sobre una empresa, cuando: a) posean la mayoría del capital suscrito de la empresa; b) dispongan de la mayoría de los votos correspondientes a las participaciones emitidas por la empresa; c) puedan designar a más de la mitad de los miembros del órgano de administración, de dirección o de supervisión de la empresa

74 Derechos concedidos por las autoridades competentes de un Estado miembro en virtud de cualquier disposición legal, reglamentaria o administrativa que tenga como efecto limitar a una o a más entidades el ejercicio de una actividad recogida en el anexo III y que afecte 
y entidades que hasta ahora en nuestro ordenamiento interno no tienen atribuida la competencia para celebrar contratos de gestión de servicios públicos en su modalidad de concesión. Recordemos que el artículo 8 del TRLCSP faculta para celebrar contratos de gestión de servicios públicos a las Administraciones públicas, o una Mutua de Accidentes de Trabajo y Enfermedades Profesionales de la Seguridad Social que sólo podrán realizar este tipo de contrato respecto a la gestión de la prestación de asistencia sanitaria.

Hecho que nos lleva a preguntarnos si deben de abandonarse los planteamientos típicos del derecho administrativo para instalar en la contratación pública un esquema iusprivatista con ciertos mecanismos en manos de los entes adjudicadores y de los órganos responsables de los procedimientos para cumplir con los principios y exigencias del Derecho comunitario. O, por el contrario, ¿debe retornarse hasta donde sea posible al Derecho administrativo?

Sería conveniente por ello que en la fase de transposición de las Directivas sobre contratación pública el legislador aprovechara la ocasión para llevar a cabo una recomposición de la organización, naturaleza y papel de los entes públicos y de sus formas de actuar, de manera que la verdadera contratación pública se desarrolle por entes insertos en la Administración sujetos al Derecho Administrativo, dotados de las potestades necesarias para una mejor gestión de todo el proceso contractual. También sería necesario reconducir la utilización de personificaciones privadas a aquellas actividades del sector público que sean pura y plenamente industriales o mercantiles, es decir, absolutamente sometidas a las leyes del mercado. En correlación con las opciones constitucionales de intervención del sector público en la economía, si verdaderamente resulta necesario y rentable para interés público.

De esta forma se eliminaría el recurso a la utilización de determinadas figuras jurídicas con el fin subyacente de prescindir de fiscalizaciones, de ortodoxia presupuestaria y contabilidad pública, y de limitaciones y exigencias en el reclutamiento de personal propias de la Administración pública. Desenmarañando así la actual dialéctica de contratos públicos/contratos privados; contratos sometidos a regulación armonizada/ contratos no sujetos a regulación armonizada. Lo que supondría un rearme ético y de integridad de la actuación administrativa. Esa reconducción y reconstrucción por la senda administrativa sustentadas en la ineludible profesionalidad e independencia de los servidores públicos y en el marco de una nueva gestión pública presidida por la transparencia, integridad y eficiencia, coadyuvarán a dignificar y potenciar la contratación pública en beneficio del interés general.

Tampoco debería el legislador español dejar pasar la oportunidad para extender el recurso especial en materia de contratación a un mayor número de contratos. La tutela judicial como derecho fundamental no puede quedar supeditada para ser efectiva exclusivamente a la cuantía del contrato. Con ello las autoridades españolas ponen de manifiesto su exclusiva preocupación por las hipotéticas condenas del TJUE en lugar de defender de forma objetiva los intereses generales.

Por último, a pesar de que la doctrina general del contrato administrativo se ha construido siguiendo las pautas trazadas por el Derecho Civil, introduciendo en cada fase del contrato las necesarias modulaciones exigidas por la peculiar manera de ser del sujeto contratante y, muy especialmente, por la distinta finalidad perseguida ${ }^{75}$, la normativa española sobre contratos del sector público desconoce el concepto de rescisión, contemplado en otras etapas históricas anteriores. En la esfera del Derecho Administrativo no se ha llegado a depurar conceptualmente las diferencias entre rescisión y resolución del contrato, mientras en el campo del Derecho privado es admitida la diferencia por los distintos efectos jurídicos que su aplicación produce. La utilización indistinta de ambas figuras como si fueran figuras similares e idénticas no es la mejor forma de aportar seguridad jurídica, teniendo en cuenta que la doctrina y la jurisprudencia suelen atribuirles efectos jurídicos distintos. En el Derecho Civil existe cierto consenso de que no deben utilizarse como unívocas ambas expresiones.

sustancialmente a la capacidad de las demás entidades de ejercer dicha actividad (artículo. 4.3 de la propuesta de directiva).

75 Las modulaciones contractuales introducidas en la normativa del sector público han propiciado algunas diferencias específicas, habitualmente recogidas de forma expresa en la normativa pública para evitar la aplicación subsidiaria del Código Civil. 